\title{
Las directrices revisadas de la Comisión de Venecia sobre la celebración de referendos*
}

\section{The revised guidelines on the holding of referendums adopted by the Venice Commission}

\author{
Daniel López Rubio \\ Universidad Carlos III de Madrid \\ ORCID ID 0000-0003-2718-4906 \\ dalopezr@der-pu.uc3m.es
}

\section{Cita recomendada:}

López Rubio, D. (2021). Las directrices revisadas de la Comisión de Venecia sobre la celebración de referendos. Eunomía. Revista en Cultura de la Legalidad, 21, pp. 12-35.

doi: https://doi.org/10.20318/eunomia.2021.6339

Recibido / received: 19/04/202 Aceptado / accepted: 10/06/2021

\begin{abstract}
Resumen
En octubre de 2020 la Comisión de Venecia aprobó una revisión de sus Directrices sobre la celebración de referendos, que databan de 2007. Sin entrar en la mayor o menor oportunidad de incorporar estos mecanismos de participación en los ordenamientos internos de los países miembros del Consejo de Europa, las Directrices establecen una serie de garantías normativas que habrán de estar presentes en los mismos para garantizar su pleno encaje con los derechos humanos, la democracia y el Estado de Derecho. Se analizarán, así, novedades en materias como la igualdad de oportunidades entre las distintas partes en las campañas previas a todo referéndum; la financiación y la transparencia de tales campañas; la claridad de la pregunta; o el ineludible respeto al marco constitucional de toda convocatoria de referéndum.
\end{abstract}

\section{Palabras clave}

Referéndum, iniciativa popular, democracia directa, principio de claridad, Comisión de Venecia, Estado de Derecho.

\footnotetext{
* Acción financiada por la Comunidad de Madrid a través de la línea de "Excelencia del Profesorado Universitario" del Convenio Plurianual con la UC3M (EPUC3MXX), en el marco del V PRICIT (V Plan Regional de Investigación Científica e Innovación Tecnológica)
} 


\begin{abstract}
In October 2020, revised guidelines on the holding of referendums were adopted by the Venice Commission, being the original ones approved back in 2007. Without discussing the convenience of introducing these mechanisms for citizen participation into the domestic law of the members of the European Council, the guidelines establish a set of legal guarantees that must be met by domestic law in order to respect Human Rights, democratic principles and the rule of law. We will thereby analyse the updates introduced on equal opportunities among the contending parties in referendum campaigns; the funding and transparency of such campaigns; the clarity of the question; or the inevitable respect for the constitutional framework by the call for a referendum.
\end{abstract}

\title{
Keywords
}

Referendum, popular initiative, direct democracy, clarity principle, Venice Commission, Rule of law.

\begin{abstract}
SUMARIO. 1. Introducción. 2. Novedades relativas a los principios del patrimonio electoral europeo. 2.1. Sufragio igual. 2.2 Sufragio libre. 3. Novedades relativas a las condiciones para la aplicación de los principios del patrimonio electoral europeo. 4. Novedades relativas a las normas específicas previstas en las Directrices. 5. Conclusiones.
\end{abstract}

\section{Introducción}

El año 2006 la Comisión de Venecia aprobó un Código de Buenas Prácticas sobre Referendos, lo que incluía unas Directrices sobre el adecuado empleo de la institución y un memorando explicativo de las mismas. El 27 de noviembre de 2008, el Comité de Ministros del Consejo de Europa aprobó una Declaración relativa al Código con el fin de invitar a las autoridades de todos los Estados miembros de la organización a guiarse por el mismo en su práctica referendaria.

Desde el año 2015 se han sucedido diversos referendos que, por unos motivos o por otros, han causado controversia. Hablamos, en efecto, del rechazo del pueblo griego al plan de rescate diseñado por la Troika (julio de 2015); la negativa de los ciudadanos holandeses a ratificar el convenio comercial suscrito entre la Unión Europea y Ucrania (abril de 2016); la salida de la Unión Europea aprobada por el Reino Unido (junio de 2016); el rechazo de los húngaros al reparto de refugiados acordado por las instituciones europeas (octubre de 2016); el fracaso del plan de paz firmado entre el Gobierno colombiano y las FARC (octubre de 2016); o la derrota del plan Renzi-Boschi para la reforma de la Constitución italiana (diciembre de 2016).

A finales del año 2016 la Comisión de Venecia manifestaba su preocupación -tanto desde la perspectiva formal como material- por el empleo del instrumento y decidía dar los primeros pasos para actualizar el Código de Buenas Prácticas. Para dotar al proceso de mayor amplitud, la Comisión remitió a todos los Estados miembros un cuestionario sobre los acontecimientos recientes en el ámbito de los referendos, solicitando su cumplimentación ${ }^{1}$. Se decide, igualmente, realizar una compilación de todas las opiniones que la Comisión había venido emitiendo sobre procesos referendarios concretos, para facilitar su difusión y consulta ${ }^{2}$. Finalmente, la Asamblea Parlamentaria del Consejo de Europa aprueba en enero de 2019 la Resolución titulada «Actualización de las Directrices para garantizar la celebración de referendos justos en los Estados miembros del Consejo de Europa». En ella, la Asamblea

\footnotetext{
${ }^{1}$ Accesible en: https://www.venice.coe.int/webforms/documents/?pdf=CDL(2018)042-e

2 Accesible en: $\underline{\text { https://www.venice.coe.int/webforms/documents/?pdf=CDL-PI(2017)001-e }}$
} 
manifiesta su satisfacción por el hecho de que la Comisión de Venecia pusiera en marcha el proceso de renovación del Código de 2006 e invita a esta a tener en cuenta en el proceso ciertos principios básicos, a saber:

1) El referéndum debe emplearse como complemento al sistema de democracia representativa, no como instrumento para circunvalar al Parlamento.

2) Las preguntas planteadas a los electores siempre deben ser claras, siendo preciso su sometimiento a un riguroso control previo que garantice la adecuada manifestación de la voluntad popular.

3) La campaña previa a la votación referendaria debe garantizar un equilibrio entre las diferentes posiciones en torno a la pregunta, permitiendo a los electores acceder a información suficiente e imparcial de cara a la formación de su opinión.

Sobre esta base, la Comisión nombra seis ponentes encargados de actualizar las Directrices. Su propuesta final sería aprobada por la Comisión en su $124^{\text {a }}$ Sesión Plenaria los días 8 y 9 de octubre de $2020^{3}$. Conviene subrayar que en la fecha en que ha sido redactado este artículo la Comisión todavía no ha aprobado el Memorando que servirá para explicar en detalle las Directrices, y que junto a ellas constituirán el nuevo Código de Buenas Prácticas. Pese a ello, el documento presenta suficiente nivel de concreción como para permitirnos una reflexión de profundidad, y a ello dedicaremos nuestro trabajo.

Las Directrices aprobadas arrancan con una introducción de la que algunas ideas merecen ser comentadas. Así, en primer lugar, el documento parte del principio de autonomía constitucional de los Estados en materia de referéndum. Ello implica que corresponde al derecho constitucional nacional determinar en qué casos se prevé la posibilidad de convocar referendos, así como su alcance, efectos y procedimiento de celebración. Las Directrices no entran a valorar la conveniencia u oportunidad de recurrir al instrumento referendario, dejando libertad al respecto a cada Estado miembro ${ }^{4}$. Su finalidad es, exclusivamente, asentar una serie de garantías básicas que deberán respetarse en todo caso para asegurar que el referéndum encuentra su mejor encaje con el Estado de Derecho, la democracia y los derechos humanos.

En segundo lugar, y retomando uno de los ejes asentados por la Asamblea en su resolución, se insiste en el papel predominante que asume la democracia representativa en los sistemas constitucionales de los países que conforman el Consejo de Europa. Nótese que esto es cierto incluso en aquellos Estados que más privilegian los instrumentos de participación directa, como es el caso de Suiza, donde el referéndum se inserta en un preponderante y bien asentado modelo representativo ${ }^{5}$. El referéndum tendría, en consecuencia, la misión de complementar, en la medida en que se considere necesario, los mecanismos de la democracia operada a través de representantes. Por ello, dice el documento, es preciso encontrar un encaje de la figura lo más armonioso posible con las estructuras representativas,

\footnotetext{
${ }^{3}$ Accesible en: https://www.venice.coe.int/webforms/documents/?pdf=CDL-AD(2020)031-e

${ }^{4}$ En su opinión de 2015 sobre Trento, relativa a una propuesta ciudadana sobre el incremento de los instrumentos de democracia directa y participativa en la provincia italiana, la Comisión recordaba que «no existe un estándar internacional (o europeo) sobre el alcance que debe ser dado a los instrumentos de democracia directa a nivel nacional, regional o local». Reconociendo que existe, en todo caso, «una tendencia a extenderlos, especialmente en el ámbito subestatal», la Comisión hacía especial énfasis en que estas herramientas de democracia directa y participativa «deben ser vistas como "un complemento a la democracia representativa"». Véase Opinion on the Citizens' bill on the regulation of public participation, citizens' bills, referendums and popular initiatives and amendments to the Provincial Electoral Law of the Autonomous Province of Trento (Italy), accessible en: https://www.venice.coe.int/webforms/documents/?pdf=CDL-AD(2015)009-e

${ }_{5}$ Como explica Sáenz Royo (2016, p. 74), la mayoría de la legislación en Suiza es aprobada por el Parlamento sin interferencia de los votantes. El 93\% de las leyes susceptibles de ser fiscalizadas por el pueblo en referéndum son aprobadas sin su intervención.
} 
lo que exige no excluir la participación de éstas en el proceso referendario. Además, la institución no debería emplearse nunca con el fin de alterar o evitar los pesos y contrapesos constitucionales.

Finalmente, la introducción establece que los referendos podrán asumir carácter constitucional, legislativo o administrativo. También podrían referirse a un tratado internacional $\mathrm{o}$, incluso, a cuestiones territoriales tales como la creación, fusión o secesión de entes infraestatales. Nos interesa destacar, en relación con esta última posibilidad, la relativa al empleo del referéndum para preguntar a los electores sobre la escisión de una entidad territorial de un Estado, que el documento hace especial hincapié en que una consulta tal solo podría celebrarse «en aquellos casos excepcionales en los que la constitución nacional lo permita». En efecto, como comprobaremos a lo largo de nuestro trabajo, una de las principales novedades del nuevo texto reside en el gran énfasis realizado sobre la necesidad de que los referendos se convoquen siempre desde el más absoluto respeto al Estado de Derecho. Parece evidente que la consulta independentista catalana de 2017, ilegal en forma y fondo, tuvo un peso relevante en la Comisión a la hora de actualizar las Directrices aquí estudiadas.

Realizada esta breve introducción, dedicaremos los apartados siguientes al estudio pormenorizado de las principales novedades introducidas por las Directrices en sus tres grandes apartados: principios del patrimonio electoral europeo; condiciones para la aplicación de tales principios; y normas específicas.

\section{Novedades relativas a los principios del patrimonio electoral europeo}

Las Directrices sobre la celebración de referendos arrancan con un primer apartado dedicado a los principios del patrimonio electoral europeo, centrados en las características del derecho de sufragio -universal, igual, libre y secreto- y en las consecuencias que de ellas se extraen.

En lo relativo a la universalidad del voto el nuevo Código no introduce novedades. Evidentemente perdura la regla general de que todas las personas tienen derecho a votar, siendo posible en todo caso el sometimiento de tal derecho a ciertas condiciones. Entre ellas destacan la edad, la nacionalidad o la residencia. Se mantiene, igualmente, la posibilidad de privar a los electores de su derecho en casos de incapacidad mental o condena por delito grave, siempre que tales causas vengan recogidas en la ley, respeten el principio de proporcionalidad y sean aplicadas por un órgano judicial. Sí aparecen innovaciones de calado en el ámbito del sufragio igual y del sufragio libre, y a ello dedicaremos las siguientes páginas.

\subsection{Sufragio igual}

En este punto, las Directrices ponen énfasis en la necesidad de garantizar la igualdad de oportunidades entre los partidarios y los oponentes de la propuesta que va a ser sometida a votación. Para ello, se dice, es preciso que las autoridades asuman una actitud neutral en relación con la campaña y su financiación, la publicidad y la cobertura en los medios de comunicación, y el derecho a manifestarse en la vía pública. Aunque estos elementos ya figuraban en el Código de 2006, se endurece la exigencia de que, en las emisiones de radio y televisión públicas sobre la campaña del referéndum, los partidarios y los oponentes de la propuesta tengan un igual acceso. Antes se consideraba tal igualdad un valor aconsejable. Ahora el documento establece que "se debe garantizar» (punto 2.2, letra b). Se considera, pues, que al margen del número y peso de los apoyos que pueda tener cada una de las partes, la 
salud de la deliberación pública previa a la votación exige que ambas tengan idénticas posibilidades para expresar sus argumentos ante los ciudadanos.

Esta regla es aplicada en Irlanda desde el año 2000, cuando la sentencia del Tribunal Supremo irlandés en el caso Coughlan v. Broadcasting Complaints Commission and R.T.É estableció la necesidad de conceder los mismos tiempos de emisión televisiva a los que apoyan la propuesta y a los que la rechazan, al margen de su representatividad parlamentaria (Barrett, 2020, p. 72; Sáenz Royo, 2018, p. 130). En el caso español, sin embargo, la Ley Orgánica $2 / 1980$, reguladora de las distintas modalidades de referéndum, ha optado por un criterio de reparto proporcional, al que además solo pueden acceder aquellas fuerzas políticas que cuenten con representación parlamentaria (artículo 14.1). Aplican el mismo sistema países como Dinamarca o Finlandia.

Un aspecto clave en el ámbito de la igualdad de oportunidades es el acceso a la financiación pública. En este punto las Directrices, clarificando su redacción anterior, establecen que la igualdad en términos de subvenciones públicas puede ser alcanzada de dos maneras: i) a través de una financiación equitativa de los partidos políticos; o ii) a través de una financiación equitativa de las organizaciones que apoyen cualquiera de las respuestas a la pregunta planteada a los electores (punto 2.2, letra d). Podría decirse que aquí el documento es algo más conservador que en lo relativo a la emisión de mensajes en los medios de comunicación públicos. Se deja la puerta abierta a que la igualdad en la financiación se produzca únicamente entre los partidos, lo que podría provocar una descompensación en el proceso deliberativo previo a la consulta. En efecto, si la mayoría de los partidos apoyaran la misma postura ante la pregunta, el grueso de la financiación pública iría en respaldo de la misma, teniendo la otra parte un relevante hándicap para hacer llegar sus argumentos a los ciudadanos.

La Political Parties, Elections and Referendums Act del Reino Unido, que data del año 2000, establece en su artículo 110 que la Comisión electoral podrá conceder una subvención única por el mismo importe a cada una de las dos organizaciones designadas para aglutinar a los partidarios del «sí» y del «no» en cada proceso referendario (con un máximo de 600.000 libras) ${ }^{6}$. En España la Ley Orgánica presenta una notable laguna en la materia ${ }^{7}$, que ha sido cubierta por normas reglamentarias aplicables a cada referéndum ${ }^{8}$. Tales normas han optado por fijar un reparto de subvenciones en favor de los partidos y proporcional a su peso parlamentario. Ello ha provocado que en referendos como el del Tratado Constitucional Europeo (2005), el desequilibrio global en la financiación de las fuerzas partidarias y opositoras de la

\footnotetext{
${ }^{6}$ Seijas Villadangos (2020, p. 133) analiza en profundidad esta y otras prerrogativas de las designated or umbrella organisations.

${ }^{7}$ En opinión de Sáenz Royo (2018, p. 44) la ausencia de una regulación general de la cuestión relativa a la financiación pública en la campaña previa a los referendos supone «una clara evidencia del papel secundario que esta figura ha desempeñado en España y del escaso interés que los partidos políticos han demostrado hacia ella».

8 Véanse el Real Decreto 6/2005, de 14 de enero, por el que se regula la concesión de ayudas extraordinarias a los grupos políticos con representación parlamentaria en el Congreso de los Diputados, para sufragar los gastos ocasionados por la explicación y divulgación pública del Tratado por el que se establece una Constitución para Europa, el Decreto 11/2007, de 16 de enero, por el que se regula y convoca la concesión de ayudas a los grupos políticos con representación en el Parlamento de Andalucía para sufragar los gastos ocasionados por la información, explicación y divulgación de la reforma del Estatuto de Autonomía para Andalucía, o el Decreto 172/2006, de 18 de mayo, por el que se establece una línea de ayudas a los grupos políticos con representación parlamentaria en el Parlamento de Cataluña para subvencionar los gastos ocasionados por la explicación y divulgación de la reforma del Estatuto de autonomía de Cataluña.
} 
cuestión haya sido manifiesto, con las consecuencias que ello tiene de cara al proceso deliberativo previo a la votación ${ }^{9}$.

Las Directrices mantienen la exigencia de que la financiación de las campañas previas a las votaciones referendarias sea transparente, pero introduce una novedad relevante. Se exige que el conocimiento de los términos de la financiación de las campañas se haga público antes de la votación (punto 2.2, letra h). Este es un aspecto de gran importancia para la formación de la voluntad de los electores. En efecto, los ciudadanos apoyan en gran medida su proceso de decisión en los conocidos como «atajos informativos». Es decir, se utilizan datos como la posición de cada uno de los partidos políticos, medios de comunicación, líderes de opinión, etc., a la hora de forjar su propio criterio $^{10}$. De este modo, aunque la información oficial sobre la propuesta en cuestión es de gran importancia ${ }^{11}$, la escasez de tiempo lleva a los ciudadanos a emplear estos métodos heurísticos para dar forma a su voto.

Al respecto de estos mecanismos es inevitable preguntarse: ¿son estas herramientas útiles para adoptar una decisión equivalente a aquella que adoptaríamos sobre la base de una información exhaustiva sobre la medida discutida? Lupia y Johnston (2001, p. 197-199) han estudiado la cuestión y han concluido que sí. Sobre la base de cinco votaciones celebradas en el estado de California en materia de regulación de la industria de seguros, confirmaron que aquellos votantes que, pese a no poseer una información exhaustiva sobre cada una de las proposiciones en liza, sí conocían la postura mantenida al respecto por la propia industria de seguros, emitían un voto muy similar al de los electores que sí disponían de información completa. Por ello, cuestiones como la publicidad de la financiación de las campañas aportaría una valiosa herramienta a los ciudadanos para forjar una decisión. Merece la pena insistir en que no estamos sugiriendo que el empleo de estos atajos deba llevar al legislador a adoptar una posición conformista en materia de información al votante. Esta información sigue siendo de gran importancia, pero asumiendo la realidad de que los ciudadanos emplean con frecuencia métodos heurísticos para adoptar decisiones, cuanta más información sobre el desarrollo y financiación de la campaña posean más exitoso será el proceso de decisión.

Finalmente, en materia de financiación las nuevas Directrices mantienen la previsión de que el principio de igualdad de oportunidades puede llevar a una limitación de los gastos de los partidos políticos y del resto de partes implicadas en el debate del referéndum. Ahora bien, introducen como novedad la posibilidad de establecer limitaciones a las donaciones individuales, así como del importe total de todas las donaciones (punto 2.2, letra i). Sobre lo primero constituye de nuevo un

\footnotetext{
${ }^{9}$ López Hernández (2017, p. 31) afirma que el hecho de que los dos grandes partidos en aquel momento (Partido Socialista Obrero Español y Partido Popular), que contaban con un $89,14 \%$ de los escaños, estuvieran a favor de la ratificación del nuevo Tratado europeo provocó una desproporción manifiesta en la campaña, tanto en lo relativo a su acceso a los medios de comunicación públicos como en la obtención de subvenciones.

10 Sobre el particular, Font y Gómez Fortes (2014, p. 222), explican: «lgual que en un proceso electoral no atendemos solo a si el Gobierno ha logrado o no buenos resultados económicos y juzgamos sus éxitos y sus fracasos con las gafas sesgadas de nuestra ideología y sentimientos partidistas, lo mismo exactamente ocurre en los referéndums».

${ }^{11}$ Las Directrices mantienen en este aspecto su redacción primigenia, llamando el punto 3.1, letra e), a las autoridades públicas a «proporcionar información equilibrada». Ello abarcaría no solo el texto sometido a referéndum, sino también «un informe explicativo o material equilibrado de campaña de parte de los partidarios y detractores de la propuesta».
} 
buen ejemplo la Political Parties, Elections and Referendums Act del Reino Unido, que establece los siguientes límites ${ }^{12}$ :

i) Las organizaciones designadas para aglutinar a los partidarios del "sí" y del "no" podrán gastar un máximo de cinco millones de libras.

ii) Los partidos políticos que se registren ante la Comisión electoral para participar en la campaña podrán gastar un máximo que variará en función de sus resultados en las últimas elecciones generales, desde un máximo de cinco millones de libras para aquellos que superaran el $30 \%$ de los votos a un mínimo de medio millón.

iii) Los demás participantes registrados ante la Comisión para participar en la campaña podrán gastar un máximo de medio millón de libras.

iv) Todas aquellas entidades no registradas tendrán un máximo de diez mil libras para gastar.

Sobre limitación de las donaciones el texto británico nada dice. Sí se establece en todo caso la necesidad de que las entidades registradas para participar en la campaña declaren todas aquellas donaciones que excedan las 7.500 libras (Anexo 15 de la Ley). Tal regla no aplica para los partidos políticos, aunque la Ley prevé que éstos declaren cuatrimestralmente las donaciones que reciben (art. 62).

\subsection{Sufragio libre}

En el ámbito del sufragio libre también hay novedades de relevancia. En primer lugar, el punto 3.1 letra a) añade al deber de las autoridades administrativas de observar una posición neutral la exigencia de que ésta se mantenga «durante todo el período de campaña». Resulta evidente, en efecto, que una de las piezas claves para garantizar que los electores puedan conformar libremente su opinión es que la Administración pública no asuma como propia ninguna de las posiciones en liza en el debate previo a la votación referendaria. En última instancia estamos ante una derivada del deber constitucional de objetividad que sujeta a la Administración (art. 103.1 CE).

En segundo lugar, se suavizan las limitaciones a la intervención de las autoridades públicas en la campaña. El antiguo Código decía lo siguiente al respecto: «las autoridades públicas (nacionales, regionales y locales) no deben influenciar el resultado del voto con una campaña excesiva y parcial» (punto 3.1, letra b). Las nuevas Directrices, sin embargo, prevén que «los partidos políticos y sus representantes, incluidos aquellos que son representantes electos u ocupan un cargo público, tienen derecho a participar activamente en la campaña» (punto 3.1, letra b). El cambio resulta razonable, pues parece claro que el papel de los partidos políticos y sus representantes es, precisamente, canalizar la voluntad popular y participar del debate social que se produce de manera previa a toda votación. No resulta imaginable una consulta donde los representantes políticos no puedan asumir como propia la defensa de una de las partes. Cuestión distinta es que estemos ante autoridades con responsabilidades en la organización o supervisión del propio referéndum, en cuyo caso las Directrices mantienen la posibilidad de aplicar deberes especiales de abstención.

En tercer lugar, las Directrices incorporan nuevas exigencias al deber de claridad de la pregunta sometida a votación. En efecto, se añade a la necesidad de que la pregunta sea "clara» y "no engañosa», la exigencia de que también resulte «comprensible» e «imparcial». Como es de sobra sabido, estamos ante la pieza

\footnotetext{
12 Seijas Villadangos (2020, p. 132) subraya que estos límites se aplican solo al período del proceso referendario, «con lo que deviene en un quiero y no puedo, porque la fiscalización de los gastos fuera de ese período queda en el limbo».
} 
nuclear para la defensa del voto libre por parte de los ciudadanos. Resultaría ciertamente imposible formar con libertad una opinión en torno a una consulta si la pregunta planteada fuera confusa en su terminología o se encontrara sesgada en favor de una de las posiciones en liza.

Como he señalado en otro lugar (López Rubio, 2020, p. 55-60), es posible diferenciar tres vertientes básicas del principio de claridad aplicado a la pregunta de un referéndum: i) la claridad en el planteamiento general de la pregunta; ii) la claridad en la terminología empleada; y iii) la claridad en las alternativas planteadas.

En efecto, en primer lugar, el planteamiento general de la pregunta debe ser sencillo y apelar a una única cuestión. Por ello, no deben añadirse en la papeleta otros comentarios o afirmaciones, sino una mera interrogación breve y sencilla. El ejemplo perfecto de pregunta contraria al principio de claridad desde esta perspectiva sería la realizada en el referéndum español sobre la pertenencia a la OTAN en 1986. En aquel caso se incluyó en la papeleta el siguiente comentario previo, en el que el Gobierno manifestaba su posición sobre la conveniencia de la permanencia en la organización:

El Gobierno considera conveniente, para los intereses nacionales, que España permanezca en la Alianza Atlántica, y acuerda que dicha permanencia se establezca en los siguientes términos:

1. ${ }^{\circ}$ La participación de España en la Alianza Atlántica no incluirá su incorporación a la estructura militar integrada.

2. ${ }^{\circ}$ Se mantendrá la prohibición de instalar, almacenar o introducir armas nucleares en territorio español.

3. Se procederá a la reducción progresiva de la presencia militar de los Estados Unidos en España.

Tras esta larga introducción, se formulaba la siguiente pregunta:

¿Considera de acuerdo con los intereses generales de España la permanencia en la Alianza Atlántica, según la posición del Gobierno arriba indicada?

Como parece evidente, un planteamiento de ese tipo no satisfaría la exigencia que realizan las Directrices de que la pregunta resulte «imparcial» y «no sugiera una respuesta». Como ha escrito Sáenz Royo (2016, p. 138), la vinculación de la pregunta a la posición del Gobierno impedía centrar la deliberación pública en las ventajas e inconvenientes de la pertenencia a la OTAN, quedando centrada en las condiciones de tal pertenencia puestas sobre la mesa por el Gobierno.

También desde la perspectiva del planteamiento general resulta necesario, como decíamos, que la pregunta haga referencia a una única cuestión. El texto de la Comisión de Venecia, tanto en su versión antigua como en la nueva, indica en su punto III.2 la necesidad de que exista «una conexión intrínseca entre las diversas partes de cada pregunta sometida a votación, a fin de garantizar el libre sufragio del votante, quien no debe ser llamado a aceptar o rechazar en su conjunto disposiciones sin un vínculo intrínseco». En efecto, si una pregunta somete multitud de elementos dispares a la valoración de los ciudadanos ello dificulta enormemente a éstos la formación de un juicio claro. Podrían estar a favor de determinados elementos y en contra de otros, con la consecuente dificultad de concluir un juicio global sobre ellos, llevando a la conversión de la consulta en un simple plebiscito en torno a las autoridades gobernantes.

Las Directrices son conscientes de que ésta última limitación no aplica a supuestos de revisión total de un texto, constitucional o legislativo. En estos casos, 
por la propia configuración del proceso, es inevitable que los ciudadanos deban realizar una valoración conjunta de multitud de cuestiones diversas. Por poner un ejemplo reciente, en el referéndum sobre la reforma constitucional impulsada por el primer ministro italiano Matteo Renzi en 2016, los electores debían pronunciarse sobre asuntos tan dispares como: la organización parlamentaria, la configuración del referéndum derogatorio, las facultades normativas del gobierno, la presidencia de la República, la administración pública, la organización territorial, la Corte Constitucional, etc. ${ }^{13}$.

El mismo problema enfrentan votaciones sobre la ratificación de tratados internacionales. Así ha ocurrido en los referendos celebrados en países europeos sobre los diversos tratados de la Unión: multitud de artículos sobre elementos heterogéneos, en muchos casos de una gran complejidad técnica.

En segundo lugar, nos encontramos con la claridad en la concreta terminología empleada. Aquí resulta imprescindible que la pregunta esté planteada con un lenguaje sencillo, comprensible para los electores y lo más imparcial posible entre las posturas enfrentadas. De este modo, se deberá renunciar al empleo de términos excesivamente complejos, así como de tecnicismos jurídicos. Un ejemplo de pregunta poco clara desde esta perspectiva fue la empleada en Grecia en el referéndum de 2015 sobre el rescate financiero, que decía así:

¿Debería ser aceptado el plan de acuerdo presentado por la Comisión Europea, el Banco Central Europeo y el Fondo Monetario Internacional en el Eurogrupo del 25 de junio de 2015, comprendido por dos partes, las cuales constituyen su propuesta conjunta? El primer documento se titula Reformas para la realización del programa actual y los ulteriores y, el segundo, Análisis preliminar de sostenibilidad de la deuda.

Sobre el empleo de términos lo más imparciales posibles en relación con las posturas en juego destaca muy especialmente la rigurosa labor emprendida por la Comisión electoral del Reino Unido ${ }^{14}$. Su dictamen sobre la pregunta del referéndum de independencia de Escocia de 2014 es un ejemplo de control riguroso sobre la claridad de la pregunta. La Comisión emitió un informe de casi cincuenta páginas ${ }^{15}$ en el que evaluaba la pregunta propuesta, que rezaba así:

¿Está de acuerdo en que Escocia debería ser un país independiente?

La Comisión establece en el punto 1.16 de su informe que basará su evaluación en cuatro pilares esenciales: i) la ejecución de estudios de opinión entre la ciudadanía escocesa, empleando muestras de gran representatividad; ii) el apoyo de expertos en accesibilidad y sencillez del lenguaje; iii) la consulta a las organizaciones interesadas y a los partidos políticos; y iv) la valoración de las quejas individuales y colectivas recibidas. Con estas herramientas, el órgano valora que la

\footnotetext{
${ }^{13}$ Llegó a plantearse en aquel caso la división (spacchettamento) de la consulta popular en tres grandes paquetes temáticos: reforma parlamentaria; Administración; y cuestión territorial. La propuesta en todo caso no tuvo recorrido, pues el texto constitucional italiano no permite tal operación de división (Lignani, 2016; Canale, 2016, p. 290). Cebrián Zazurca (2020,p. 392-393) narra cómo esta opción fue la empleada en Suiza para la reforma de su Constitución en 1999. Se decidió dividir en «tres paquetes -actualización, derechos populares y justicia-, cada uno de los cuales constituía una reforma total autónoma». Ahora bien, como el propio autor señala, esta práctica no está exenta de problemas: «la dificultad de dividir por materias, el perjuicio infligido a la coherencia del texto, determinar cómo y quién recompone ese texto, aportar una imagen de arbitrariedad o alentar en la población una falta de visión de conjunto».

${ }^{14}$ El artículo 104 de la Political Parties, Elections and Referendums Act del año 2000 establece que corresponde a esta Comisión la emisión de un informe consultivo sobre la claridad e inteligibilidad de la pregunta cuando una consulta referendaria sea propuesta.

15 Accesible en: https://www.electoralcommission.org.uk/sites/default/files/pdf file/Referendum-onindependence-for-Scotland-our-advice-on-referendum-question.pdf
} 
terminología utilizada cumpla cinco criterios (punto 5.2): i) ser fácilmente comprensible; ii) ir directa al asunto (to the point); iii) no ser ambigua; iv) ser neutral, evitando animar a los electores a considerar una opción más correcta que la otra; y v) no confundir a los votantes.

Así, la Comisión analizó palabra por palabra el enunciado propuesto, concluyendo que la expresión «¿Está de acuerdo...?» animaba a los ciudadanos a considerar más favorable la respuesta afirmativa que la negativa. $Y$ ello por tres motivos (punto 5.17): i) «es más sencillo estar de acuerdo con algo que en desacuerdo»; ii) "sugiere que la independencia de Escocia es algo bueno, al estar invitando a la gente a estar de acuerdo con ello»; y iii) «implica que la decisión ya ha sido tomada y que la independencia es inevitable». En consecuencia, la Comisión consideró conveniente sustituir la expresión por otra de mayor neutralidad, a saber:

\section{¿Debería ser Escocia un país independiente?}

La recomendación fue asumida por las autoridades escocesas, y finalmente la propuesta sugerida por la Comisión fue la aprobada en la Scottish Independence Referendum Act de 2013 (sección 1(2)).

En tercer y último lugar, es importante que la pregunta sea clara en términos de las alternativas que plantea al electorado. Como novedad, las Directrices prevén la posibilidad de que se planteen preguntas de opciones múltiples. A desarrollar esta posibilidad se dedica el apartado quinto del apartado III del documento, dedicado a Normas específicas. Por una cuestión de unidad temática, trataremos ahora esa nueva regulación sobre las preguntas múltiples.

Estas normas específicas indican que, por regla general, las preguntas sometidas a referéndum deberán seguir un sistema binario, en el que los ciudadanos deban responder con un sí, un no o un voto en blanco. Sin embargo, se admite la posibilidad de celebrar referendos de opciones múltiples, en las que se vote sobre dos o más alternativas. A título de ejemplo, las Directrices plantean estas hipótesis: i) el Parlamento podría plantear una contrapropuesta a una iniciativa popular, sometiéndose a votación de manera simultánea; y ii) se podrían plantear en la consulta dos o más alternativas.

El primer ejemplo es una realidad en la iniciativa popular configurada en el ordenamiento suizo. En efecto, el artículo 139 de su Constitución prevé la posibilidad de que cien mil ciudadanos presenten una iniciativa popular tendente a la revisión parcial de la ley fundamental. Esta propuesta puede estar planteada en términos generales o bien a través de un proyecto articulado. Pues bien, en este segundo supuesto, la iniciativa es sometida directamente a referéndum, pudiendo el Parlamento federal ${ }^{16}$ recomendar su aprobación o su rechazo, o bien emitir una contrapropuesta que será votada en unidad de acto ${ }^{17}$.

El artículo 139b desarrolla el funcionamiento de estas contrapropuestas. Prevé que los ciudadanos puedan, si así lo desean, votar a favor de ambos proyectos. Como indica Kobach (1994, p. 104), hasta 1987 los electores solo podían pronunciarse a favor de una de las dos propuestas. Ello podía generar la existencia de «propuestas

\footnotetext{
${ }^{16}$ Cebrián Zazurca (2020, p. 387) subraya que, aunque la competencia formal para la presentación de la contrapropuesta recae en la Asamblea Federal, el Ejecutivo puede también presentar sugerencias.

17 Como señala Gross (2007, p. 69), se genera una cultura más cooperativa, menos antagonista, «si el Parlamento viene obligado a discutir la iniciativa ciudadana, tiene que votarla e incluso tiene el derecho de reaccionar a ella con su propia propuesta, permitiendo que el asunto sea enfocado desde una nueva perspectiva».
} 
señuelo», en las que el Parlamento incluía alguna de las reclamaciones de los proponentes, dividiendo el voto de los partidarios del cambio, lo que terminaba por favorecer el mantenimiento del statu quo. Ante la eventualidad de que ambas alternativas, la popular y la parlamentaria, resulten aprobadas por el cuerpo electoral, se prevé una cuestión subsidiaria en la que los ciudadanos deben indicar a cuál de las dos propuestas dan preferencia.

El segundo ejemplo planteado por las Directrices, que pasa por la formulación de preguntas con opciones múltiples ofrece, como han señalado Lupia y Johnson (2001, p. 209) dos problemas relevantes. En primer lugar, exige un esfuerzo a las autoridades para facilitar información suficiente que permita al elector formarse una opinión. En paralelo, los ciudadanos deberán dedicar un mayor tiempo a informarse. En segundo lugar, este tipo de preguntas pueden plantear dificultades para declarar una opción ganadora.

Paradigma de esto último resultan los referendos de preguntas sucesivas, como el celebrado en Puerto Rico en 2012. En aquel caso se planteaban dos preguntas: en la primera se pedía al elector su opinión sobre mantener o no la condición política actual de Puerto Rico (Estado libre asociado sujeto a la autoridad territorial de los Estados Unidos); y en la segunda se podía elegir una de las siguientes tres alternativas no territoriales: estadidad (pasar a ser un Estado más de los Estados Unidos, con plenitud de derechos como tal), Estado libre asociado pero soberano, o Estado independiente.

La votación registró ${ }^{18}$, en la primera pregunta, un $54 \%$ de sufragios contrarios al mantenimiento del statu quo. En la segunda pregunta, la estatidad obtuvo el respaldo de un $61,2 \%$ de los ciudadanos, frente a un $33,3 \%$ en favor de la opción de Estado libre asociado soberano y un $5,5 \%$ en favor de la independencia total. Pues bien, este formato de consulta plantea muchos interrogantes en torno al apoyo popular real que recibe cada una de las opciones no territoriales planteadas. Aunque es cierto que la segunda pregunta no se planteaba como abierta solo a los ciudadanos que votaran en la primera a favor de la superación del statu quo, lo lógico parece pensar que ellos son los interesados en elegir entre las tres alternativas de cambio, no así los electores favorables a la condición territorial vigente. De hecho, en la segunda pregunta se registraron más de medio millón de votos en blanco o nulos (de un total de 1.879.202 votos). Así las cosas, con un sistema de votación de esta índole es muy discutible afirmar que un $61,2 \%$ de los puertorriqueños estaba a favor de la estadidad en el referéndum de 2012. Parecería más razonable afirmar que estaban a favor de tal opción un $61,2 \%$ de los ciudadanos que se habían manifestado en contra del statu quo. En definitiva, el método de las preguntas sucesivas plantea no pocos problemas en relación con la proclamación de una alternativa como ganadora.

Cabe decir, de hecho, que este tipo de planteamiento ha sido superado en Puerto Rico, pues las siguientes votaciones realizadas en la materia han seguido un esquema más sencillo. Así, en 2017 se dio a elegir directamente entre tres opciones: statu quo, estadidad o independencia, con un $97,1 \%$ de los sufragios en favor de convertir al país en un nuevo Estado de los Estados Unidos. Finalmente, en la votación celebrada en 2020 la pregunta se clarificó aún más, pidiendo a los ciudadanos un sí o un no a la opción de que Puerto Rico fuera admitido inmediatamente como un Estado dentro de la Unión.

18 El desglose oficial de resultados es accesible en:


Las Directrices analizadas indican que ante la pregunta del referéndum «los votantes deben poder responder (...) con un sí, un no o un voto en blanco». La experiencia británica en torno a la salida del Reino Unido de la Unión Europea ha demostrado, sin embargo, que relevantes matices pueden plantearse ante esta idea. La propuesta original sobre aquel referéndum incluía la siguiente pregunta:

\section{¿Debería el Reino Unido permanecer como miembro de la Unión Europea?}

Los ciudadanos británicos podrían responder marcando la casilla del «Sí» o la del «No». La Comisión electoral emprendió un minucioso estudio sobre la redacción de la pregunta ${ }^{19}$, utilizando los criterios comentados supra en su informe sobre la pregunta planteada para el referéndum de independencia escocés. La Comisión recibió múltiples quejas por un posible sesgo en la redacción de la pregunta en favor de la permanencia en la Unión Europea, basadas en dos argumentos: en primer lugar, el texto únicamente giraba en torno a la opción de permanecer. En segundo lugar, la opción afirmativa quedaba vinculada con el statu quo. De las consultas mantenidas con los ciudadanos, la Comisión puedo extraer la evidencia de que buena parte de los consultados en el bloque partidario de la salida de la Unión recelaban del modo en que quedaban planteadas las alternativas, concluyendo que tal percepción podría dañar la legitimidad del proceso referendario en el supuesto de que finalmente triunfara el remain (puntos 5.12, 5.13 y 5.14). Así, sugirió un planteamiento más neutral de las opciones en liza, con la siguiente redacción de la pregunta:

¿Debería el Reino Unido permanecer como miembro de la Unión Europea o abandonar la Unión Europea?

Pese a que las propuestas de la Comisión sobre la redacción de las preguntas referendarias no son vinculantes, una vez más las autoridades accedieron y dieron carácter definitivo a la recomendación. Así, los ciudadanos pudieron elegir entre dos opciones: «Permanecer como miembro de la Unión Europea» o «Abandonar la Unión Europea». Es imprescindible insistir en que en las resoluciones de la Comisión pesan múltiples factores, entre los que destaca el grueso de opiniones que se reciben sobre la pregunta, tanto de los electores como de diversos expertos y organizaciones interesadas en el proceso. Así, esta concreta recomendación sobre el cambio de planteamiento de las alternativas propuestas al electorado bien podría no ser aplicable a otro proceso, donde la oferta «Sí/No» podría ser aceptable. La mejor conclusión que puede extraerse del ejemplo británico es la conveniencia de activar un concreto proceso de reflexión para cada referéndum, permitiendo ponderar las diversas circunstancias del caso en aras de una mejor protección del principio de claridad.

Precisamente una novedad relevante en las Directrices estriba en la inclusión en el punto 3.1, letra d), de la exigencia de que «un organismo imparcial» deba «ejercer un control previo sobre la claridad de la pregunta». Volveremos sobre esta cuestión en el siguiente epígrafe, dado que el texto dedica un apartado específico de su segunda parte a glosar las competencias de organización y supervisión del referéndum por un órgano imparcial. Queda claro, en todo caso, el carácter nuclear del principio de claridad en todo procedimiento de referéndum, pues en ausencia del mismo el mecanismo es susceptible de las más penosas manipulaciones.

19 Accesible en: https://www.electoralcommission.org.uk/sites/default/files/2019-08/EU-referendumquestion-assessment-report.pdf 
3. Novedades relativas a las condiciones para la aplicación de los principios del patrimonio electoral europeo

Las Directrices dedican su segunda parte a concretar las condiciones que son precisas para poder aplicarse de manera exitosa los principios anteriormente expuestos. Aquí nos encontramos, de entrada, con una novedad de grandísima importancia. El primer punto de esta segunda parte se titula El Estado de Derecho, y subraya que «el uso de los referendos debe cumplir con el sistema legal en su conjunto». En particular, «no se pueden celebrar referendos si la constitución o una ley conforme a la constitución no los prevé, por ejemplo, cuando el texto sometido a referendo es de competencia exclusiva del parlamento». Es inexcusable señalar que esta exigencia no es en rigor novedosa para el Código. La anterior versión también la recogía, pero lo hacía en su tercera parte, dedicada a las Normas específicas. El nuevo texto mantiene la necesidad de que los referendos sean siempre convocados de conformidad con el ordenamiento jurídico, pero blinda este principio elevándolo a la categoría de condición indispensable para la preservación de los principios del patrimonio electoral europeo. Empleando las palabras del profesor Castellà (2020), ponente de las nuevas Directrices, el necesario respeto al Estado de Derecho «se sitúa ahora en el frontispicio» del documento.

El origen de este cambio de estatus de la regla parece evidente: la convocatoria en Cataluña de dos consultas sobre su independencia del Reino de España (2014 y 2017), ambas contrarias a la Constitución española y el Estatuto de Autonomía de Cataluña. Como se expuso en la introducción, ya en octubre de 2016 la Comisión de Venecia se mostraba preocupada por el empleo que se estaba haciendo del referéndum, tanto desde una perspectiva material como formal. En lo concerniente a las cuestiones de procedimiento, la Comisión subrayó en aquel momento «la necesidad de que los referendos respeten el Estado de derecho y, en particular, que cumplan con el sistema jurídico en su conjunto, especialmente con las normas de procedimiento sobre la revisión constitucional» (punto 5 de la Introducción de las Directrices).

La Comisión de Venecia, como explicamos en el primer epígrafe, no emite una valoración positiva o negativa sobre el instrumento del referéndum. Afirma que dependerá de cada derecho constitucional concretar en qué supuestos puede ser conveniente la celebración de una consulta. Su labor se limita a ofrecer unas pautas de actuación básicas que garanticen que este mecanismo no devenga tiránico, cercenando los derechos humanos, la democracia o el Estado de derecho. $Y$ en ese empeño es clave la rotunda explicitación de que el referéndum no puede celebrarse a antojo de las autoridades, centrales, regionales o locales, de un país ${ }^{20}$. Su empleo deberá estar permitido por el ordenamiento jurídico, pues de lo contrario la estabilidad democrática de las naciones quedaría seriamente dañada.

Y es en esta línea que la Comisión dirige su mirada al empleo espurio que las autoridades catalanas han realizado -o intentado- del referéndum. Sin necesidad de mención expresa -otra cosa sería impropia de una guía con pretensiones de generalidad-, la introducción del documento subraya que los referendos «pueden referirse a cuestiones territoriales, como la creación o fusión de entidades subnacionales, así como a la secesión, en aquellos casos excepcionales en los que

${ }^{20}$ En su informe de 2001 sobre la situación constitucional de Yugoslavia la Comisión subrayaba que «la democracia no puede ser reducida a la simple expresión de la voluntad popular. En un Estado que respete los principios del Consejo de Europa las decisiones han de ser tomadas de acuerdo con la ley». Véase Interim Report on the Constitutional Situation of the Federal Republic of Yugoslavia, accessible en: https://www.venice.coe.int/webforms/documents/default.aspx?pdffile=CDL-INF(2001)023-e 
la constitución nacional lo permite». Se censura, pues, de manera cristalina el uso del procedimiento referendario realizado por la Generalitat de Cataluña en su desafío ilegal al Estado español.

Conviene recordar, igualmente, el relevante episodio que tuvo lugar en 2017 entre Carles Puigdemont, presidente de la Generalitat, y Gianni Buquicchio, presidente de la Comisión de Venecia. En mayo de aquel año, con el aparato independentista preparando la que sería su segunda consulta secesionista ilegal, el portavoz de SíQueEsPot, Lluís Rabell, presentó una moción parlamentaria encaminada a que el Govern de Cataluña se pusiera en contacto con la Comisión para garantizar que el eventual referéndum cumpliera con todos los estándares democráticos exigidos por la institución. El Parlament aprobó la moción ${ }^{21}$, y el presidente del ejecutivo autonómico dirigió el 29 de mayo una misiva al presidente de la Comisión comunicando su interés en realizar un referéndum pactado sobre el futuro político de Cataluña que cumpliera con las exigencias del Código de Buenas Prácticas en la materia. Se aprovechaba también para censurar la negativa del presidente del Gobierno, Mariano Rajoy, a negociar la posible convocatoria de un referéndum de este tipo, y se eludía en todo momento la determinación de las autoridades catalanas de celebrar una consulta de manera unilateral. La respuesta del presidente de la Comisión llegaba pocos días después, el 2 de junio. Tras tomar nota de su intención de cooperar con la Comisión en las modalidades de un referéndum acordado, celebraba su interés en el Código de Buenas Prácticas. A continuación, decía:

Usted es consciente, sin duda, de que no solo el referéndum, sino también su cooperación con nuestra Comisión, debe ser realizado de acuerdo con las autoridades españolas. Me gustaría subrayar que la Comisión de Venecia, cuyo nombre oficial es Comisión Europea para la Democracia a través del Derecho, ha remarcado constantemente la necesidad de que cualquier referéndum sea llevado a cabo de total conformidad con la Constitución y la legislación aplicable.

La contundencia de la respuesta, junto con el caso omiso que el President hizo de la misma los meses siguientes, eximen, creo, de mayores explicaciones sobre el sentido de la elevación de estatus que obtiene la exigencia del respeto al Estado de derecho en las nuevas Directrices.

La segunda novedad relevante en este apartado la encontramos en el punto 3 , dedicado a «niveles de regulación y estabilidad de la ley de referéndum». Junto con la exigencia de que las normas sobre referéndum tengan al menos el rango de ley, ya presente en el anterior Código, se introduce la necesidad de que "no sean adoptadas ad hoc para un referéndum específico» (letra a)). Es inevitable en este punto no volver la mirada una vez más al caso catalán. En octubre de 2017 el Parlament aprobaba la Ley 19/2017, de 6 de septiembre, del referéndum de autodeterminación. Además de su evidente inconstitucionalidad por la invasión de competencias del Estado ${ }^{22}$, la norma tenía por exclusivo objeto la regulación de un

\footnotetext{
${ }^{21}$ Moción 122/XI del Parlamento de Cataluña, sobre el cumplimiento del apartado I.1.2, «Exigencia social de celebración de un referéndum», de la Resolución 306/XI. Destacan en lo que aquí interesa los puntos 4 y 5 :

«4. El Parlamento de Cataluña insta al Gobierno de Cataluña a poner en conocimiento de la Comisión Europea para la Democracia a través de la Ley (Comisión de Venecia) la voluntad mayoritaria de los ciudadanos de Cataluña expresada en el mandato del Parlamento sobre la celebración de dicho referéndum pactado y acordado.

5. El Parlamento de Cataluña insta en este sentido al Gobierno de Cataluña a poner en marcha las iniciativas pertinentes para disponer del asesoramiento, el reconocimiento y el aval de la Comisión de Venecia en cuanto a las condiciones que debería cumplir la convocatoria del referéndum para cumplir los requisitos establecidos en su Código de buenas prácticas en materia de referéndums».

22 Invasión que sería confirmada por el Tribunal Constitucional en su sentencia 114/2017, de 17 de octubre.
} 
referéndum que sería celebrado, según su artículo 9, el 1 de octubre de 2017. La Comisión de Venecia pretende en sus nuevas recomendaciones evitar este tipo de regulaciones, pensadas para una concreta consulta, fomentando la existencia de un corpus normativo general y estable en los ordenamientos de los países miembros del Consejo de Europa ${ }^{23}$. El objetivo parece claro: evitar que la mayoría de turno pueda modular a su antojo los elementos básicos de la consulta a los ciudadanos, convirtiendo la misma en un instrumento a su servicio.

En la letra c) del mismo punto tercero encontramos otro aspecto novedoso. La Comisión indica que «la aprobación de la legislación sobre referendos debería contar con un amplio consenso, tras amplias consultas con todos los interesados». Se insiste, pues, en la misma idea, la de evitar que una mayoría puntual pueda adaptar la configuración de los procesos referendarios en su beneficio. En este punto conviene recordar que en España el artículo 92.3 de la Constitución exige que sea una Ley orgánica la que regule «las condiciones y el procedimiento de las distintas modalidades de referéndum previstas en esta Constitución». Las Directrices no contienen especificación de qué debe entenderse por amplio consenso. Resulta obvio que la regulación descarta el empleo de una mayoría simple para demandar una cualificada, siendo opinable si una mayoría absoluta como la exigida por nuestra Constitución satisfaría este nuevo requisito o si por el contrario debería elevarse aún más el umbral de aceptación parlamentaria requerido.

El aspecto donde más se innova en este segundo apartado de las Directrices es el regulado en su punto 4.1, dedicado a la «organización y supervisión por un órgano imparcial». La regulación al respecto comienza manteniendo el deber general de que «un órgano imparcial debe estar a cargo de la organización del referéndum». En este sentido, se dice, "a menos que exista una larga tradición de imparcialidad de las autoridades administrativas en materia electoral, deben crearse comisiones independientes a todos los niveles, desde el nivel nacional hasta el de las mesas electorales». Conviene, en efecto, señalar que en países como Suiza la organización del referéndum se deja a cargo de la propia Administración, pues existe una muy relevante tradición de impecable rigor e imparcialidad en la llevanza por su parte de las labores organizativas de las consultas populares ${ }^{24}$. En todo caso, lo habitual es que se asuman estas tareas por órganos independientes como las Juntas electorales en España, la Comisión electoral en Reino Unido, las Oficinas para el referéndum en Italia (junto con la Corte Constitucional), o el Consejo Constitucional en Francia.

Pues bien, la gran novedad en este punto es la previsión de un nuevo apartado b) dedicado a enumerar cuáles han de ser las competencias asumidas por ese organismo independiente, a saber:

1) Comprobar la validez de cualquier pregunta propuesta para el referéndum y aprobar su redacción final.

2) Proporcionar información oficial.

3) Hacer declaraciones públicas oficiales en tiempo real sobre violaciones o infracciones importantes a las reglas.

4) Supervisar la realización de la campaña.

${ }^{23}$ Castellà (2016, p. 305) explica que en Reino Unido la aprobación de la Political Parties, Elections and Referendum Act del año 2000 vino precisamente a solventar este problema, pues hasta el momento los referendos que se habían ido celebrando se regulaban en leyes de caso único.

${ }^{24} \mathrm{Y}$ ello pese a que, como señala Serdült (2018, p. 65), durante la campaña de referéndum el Gobierno está habilitado a difundir su criterio sobre el asunto discutido y ofrecer recomendaciones. 
5) Hacer cumplir sus decisiones y sancionar posibles infracciones.

6) Corregir una redacción defectuosa antes de la votación, en supuestos como: i) la pregunta es oscura, engañosa o sugestiva; o ii) se han violado las normas de validez procesal o sustantiva.

Se desea, en definitiva, que la asunción de esas decisiones en la organización del referéndum, capitales para la salvaguarda de la libertad e igualdad en el sufragio de los ciudadanos, no queden en manos de una autoridad parcial, singularmente el poder ejecutivo.

El texto incide igualmente en la necesidad de que los sistemas de apelación contra el organismo encargado de las acciones anteriores queden en manos de un órgano «imparcial e independiente» (punto 4.3). Tal institución, se dice, «deberá estar establecida por ley y estar obligada a aplicar la ley». La Comisión de Venecia señala que la opción preferida a este respecto en la mayoría de los Estados miembros del Consejo de Europa es la de confiar a un tribunal de justicia la apelación final. Parece evidente, en efecto, que la intervención judicial colmaría del mejor modo posible la exigencia de neutralidad e imparcialidad requerida para la apelación contra la autoridad encargada de la organización del referéndum.

\section{Novedades relativas a las normas específicas previstas en las Directrices}

Cuatro son las principales novedades que se introducen en la tercera parte de las nuevas Directrices, dedicada a la previsión de reglas específicas que disciplinen la convocatoria de referendos. Tales innovaciones se enmarcan en las siguientes materias: i) número de firmas necesario en los referendos celebrados a solicitud de una parte del electorado; ii) posibilidad de realizar referendos de opciones múltiples; iii) la estipulación de un quórum de aprobación; y iv) reglas en materia de fecha para la celebración del referéndum. El segundo de los elementos ya lo hemos discutido en nuestro epígrafe segundo, por lo que dedicaremos este último apartado a los tres elementos restantes.

La primera novedad a tener en cuenta en materia de reglas específicas es la previsión que se realiza sobre recogida de firmas para los referendos que puedan celebrarse a solicitud del cuerpo electoral y para las iniciativas populares. El texto indica que «es aconsejable exigir un número de firmas lo suficientemente elevado para que sólo se sometan a referéndum las cuestiones que interesen a una parte sustancial del electorado, salvaguardando así el carácter complementario del referéndum respecto de la democracia representativa». En todo caso, se añade, «el requisito de un número suficiente de proponentes de un referéndum no debe ser tan elevado como para que la posibilidad de un referéndum sea meramente teórica». Así pues, las Directrices tratan de evocar la idea de una cifra exigida de firmas que resulte equilibrada, sin ser tan baja como para permitir una constante convocatoria de consultas que pueda desestabilizar la acción de las autoridades representativas del país, ni tal alta como para desincentivar de manera total el control ciudadano que permite este tipo de instrumentos.

Se añade, y sin duda esta es la clave, la exigencia de que este número de firmas sea «proporcional al número de votantes registrados». Pues bien, la experiencia comparada nos ofrece interesantes datos sobre el particular. Así, en Suiza se requieren cien mil firmas para la iniciativa popular de reforma constitucional (arts. 138 y 139 de la Constitución suiza) y cincuenta mil para la solicitud de referéndum facultativo contra la aprobación de cualquier ley federal (art. 141). En proporción al tamaño del censo electoral (5.459.218 en las últimas elecciones de 
2019), tendríamos que la iniciativa popular de reforma requiere el apoyo de un $1,83 \%$ del electorado, mientras que el referéndum facultativo podría activarse por un $0,91 \%$. En Italia el referéndum abrogativo precisa la firma de quinientos mil electores (art. 75 de la Constitución italiana), lo que sobre un censo de 50,7 millones constituye algo menos de un $1 \%$ de los electores inscritos. En Francia el referéndum de iniciativa minoritaria prevé la necesidad de que apoyen la proposición de una quinta parte de los parlamentarios un $10 \%$ de los electores inscritos (art. 11 de la Constitución francesa), lo que con arreglo al censo actual (cuarenta y siete millones y medio de ciudadanos) daría un total de más de cuatro millones. En los länder alemanes se reconoce la capacidad de iniciativa popular de referéndum a un porcentaje del electorado, que va desde el $5 \%$ exigido en Brandemburgo o Schleswig-Holstein hasta el $20 \%$ en Turingia (Arias Guedón, 2020, p. 156). En Colombia pueden activar un referéndum propositivo de reforma constitucional un $5 \%$ de los electores inscritos (art. 374 de la Constitución colombiana). En Uruguay la cifra se eleva al 10\% (artículo 331.A de la Constitución uruguaya).

Como puede comprobarse la experiencia comparada ofrece ejemplos de porcentajes requeridos bien diversos. A nuestro juicio deben extraerse de aquí dos comentarios. En primer lugar, resulta imposible acotar una horquilla de porcentajes que resulte apriorísticamente razonable para la exigencia presentada por las nuevas Directrices. Corresponderá a cada Estado ponderar todas las circunstancias concurrentes para tratar de hallar un umbral equilibrado que no bloquee por completo el uso del instrumento pero que tampoco lo convierta en una práctica excesiva ${ }^{25}$. $Y$, en segundo lugar, y en desarrollo de la misma idea, será imprescindible atender al tipo de referéndum concreto que esté en juego. Parece sensato exigir un umbral de firmas mayor conforme se incremente la potencia de los efectos de la iniciativa ciudadana. Por poner un ejemplo: no es razonable que en Francia, donde los ciudadanos no pueden actuar por sí solos sino con el beneplácito de un porcentaje de parlamentarios, y donde su iniciativa puede ser desechada con un simple examen parlamentario, el umbral exigido esté fijado en el $10 \%{ }^{26}$. Resulta evidente su desproporción en relación con los efectos del procedimiento. Deberá estarse, en definitiva, a la configuración concreta del referéndum para calibrar si el nivel de apoyos ciudadanos necesarios es o no razonable, lo que abarcaría:

1) El recorrido de la solicitud: no parece lo mismo que la consecución del umbral de firmas exigido de lugar a la directa convocatoria de la consulta popular que el hecho de suponer una mera solicitud que deba contar con la autorización de las autoridades representativas.

2) Los efectos del referéndum: si éste implica o no un cambio en el ordenamiento jurídico o tan solo supone una opinión consultiva.

3) En caso de que sea un referéndum normativo, es decir, que implique innovación en el ordenamiento, deberá estarse al rango de la norma alterada,

\footnotetext{
${ }^{25}$ En palabras de Gross (2007, p. 67), la minoría habilitada para activar una consulta popular «debe ser suficientemente representativa de una parte esencial de la población, pero sin limitar el posible uso de este instrumento a grupos poderosos y partidos que ya están bien representados en las fases preparlamentaria y parlamentaria del proceso de toma de decisiones».

${ }^{26}$ Requejo Rodríguez (2020, p. 273) califica esta cifra de «excesiva», resultando «inviable culminar con éxito la activación del proceso, como prueban los hechos». La autora se refiere a que en los trece años que han transcurrido desde la aprobación constitucional del instrumento -ocho si partimos del momento de aprobación de su desarrollo legal- ninguna propuesta ha logrado satisfacer los requisitos de activación. No es de extrañar que el proyecto de reforma constitucional impulsado por el Presidente Macron en agosto de 2019 incluya la reforma del instrumento, rebajando el umbral de apoyo ciudadano requerido al millón de firmas. Véase Projet de loi constitutionnelle $n^{\circ} 2203$, pour un renouveau de la vie démocratique, accesible en: https://www.assemblee-nationale.fr/dyn/15/textes/115b2203 projetloi\#D Article 11
} 
resultando lógico que el requisito se endurezca en caso de pretender afectarse a la Constitución.

La segunda innovación a tener en cuenta implica los quórums de participación y aceptación del referéndum. Al igual que el antiguo Código, el texto considera no aconsejable la estipulación de un umbral mínimo de participación en la consulta para admitir como válido su resultado. La explicación a esta recomendación se nos ofrecía en el anterior documento de manera expresa: un quórum de participación «asemeja a los votantes que se abstienen a aquéllos que votan en contra de la propuesta». Este efecto nocivo ha sido muy habitual en el ámbito italiano, donde de los 67 referendos abrogativos convocados desde 1970, 28 han fracasado por no alcanzar el umbral de participación requerido -la mayoría de los electores inscritos ${ }^{27}$. El memorándum explicativo que formaba parte del antiguo Código ofrecía un ejemplo de cómo la fijación de un quórum de participación puede devenir problemático: imaginemos que existe un $48 \%$ de ciudadanos favorables a la medida sometida a referéndum, un $5 \%$ en contra y un $47 \%$ de abstención. Los electores contrarios a la propuesta tendrán el incentivo de no acudir a votar para hacer fracasar el procedimiento, siendo muy factible que lo logren pese a ser claramente minoritarios.

El nuevo texto, como decíamos, mantiene también la recomendación de no estipular un porcentaje mínimo de votantes que deban aprobar la medida para que ésta pueda ser exitosa (quórum de aprobación). Ahora bien, aparece como relevante innovación la previsión de dos excepciones a esta regla general. Será aceptable fijar un umbral mínimo de aprobación, en primer lugar, para aquellos referendos sobre asuntos de relevancia constitucional fundamental. Se considera que en aspectos cruciales del documento constitucional su reforma no debería poder acometerse con la simple consecución de más votos afirmativos que negativos.

Estamos ante un debate que se ha suscitado con cierta intensidad en torno a las hipótesis secesionistas. El campo que más fértil ha resultado intelectualmente para esta controversia ha sido el canadiense. En 1995 la provincia de Quebec celebraba un referéndum de secesión en el que los resultados fueron muy ajustados: $50,58 \%$ de sufragios en contra de la independencia frente a $49,42 \%$ a favor. La cercanía de la victoria de la opción secesionista condujo al Primer Ministro, Jean Chrétien, a plantear una consulta ante el Tribunal Supremo sobre la viabilidad jurídica de que la provincia acometiera unilateralmente su secesión. La respuesta del Tribunal llegará el 20 de agosto de 1998 a través de un célebre dictamen ${ }^{28}$. En él, se niega que Quebec posea un derecho a la secesión en base al Derecho Internacional, al no encajar con ninguno de los supuestos de autodeterminación en él contemplados. También se descarta que el ordenamiento interno permita a una provincia independizarse de Canadá de manera unilateral. En todo caso, se dice, los principios constitucionales no impiden una secesión, siempre que se materializa a través de los

\footnotetext{
${ }^{27}$ La reforma constitucional lanzada por el primer ministro Matteo Renzi el año 2016 contemplaba, entre otras muchas medidas, la modificación del artículo 75 del texto supremo para superar este tipo de prácticas. Se establecía que en aquellas iniciativas que lograran 800.000 firmas el quórum de participación dejaría de ser equivalente a la mayoría del cuerpo electoral, para pasar a ser la mayoría de los electores que hubieran participado en los últimos comicios a la Cámara de Diputados. En opinión de Romboli y Panizza (2016, p. 37) la propuesta era insuficiente. Si la experiencia ha acreditado el uso espurio del quórum, parece poco razonable aplicar el remedio como premio solo para algunas solicitudes en lugar de como solución general. Y es que el referéndum abrogativo «es claramente para el uso de la minoría, y el alcance de un número más alto de firmas es ciertamente más fácil para una minoría organizada que para aquella no vinculada a partidos o sindicatos, para la cual la abrogación de una ley por vía referendaria se haría más dificultosa». Como es sabido, la propuesta de reforma constitucional, pese a ser aprobada por ambas cámaras, no obtuvo el respaldo de los ciudadanos en el referéndum constitucional celebrado el 4 de diciembre de 2016 (40,88\% de los sufragios fueron favorables a la reforma, frente a un $59,12 \%$ en contra).

${ }^{28}$ Reference Re Secession of Quebec, [1998] 2 SCR 217.
} 
pasos estipulados para la reforma constitucional (párrafo 84). Sobre esa base, la pregunta clave que analiza el dictamen será la de qué efectos conferir a un eventual voto afirmativo del cuerpo electoral de una provincia en un referéndum sobre su secesión. Como decimos, el marco constitucional impide atribuir a tal resultado la capacidad de generar de manera directa y unilateral la independencia, pero el Tribunal también entiende que desde la perspectiva del principio democrático una posición tal no podría ser ignorada. Más concretamente, el Tribunal considera que una «mayoría clara» en favor de la opción independentista habría de ser tenida en cuenta por el gobierno federal, siempre que haya surgido en una consulta con una pregunta «libre de ambigüedad». (párrafo 87). Si esa doble exigencia de claridad fuera debidamente satisfecha, el voto afirmativo del electorado quebequés generaría «una recíproca obligación de todas las partes de la Confederación a negociar los cambios constitucionales que den respuesta a ese deseo» ${ }^{29}$ (párrafo 88).

Lo más destacado de estos planteamientos del Tribunal Supremo canadiense es la inconcreción del concepto de «mayoría clara». En lugar alguno se establece cuál ha de ser el umbral de aceptación para entender satisfecha la exigencia. Pues bien, tras el dictamen el gobierno federal decidió impulsar su plasmación normativa a través de un proyecto que devendrá en la célebre Ley de Claridad, de junio del año $2000^{30}$. Ocurre, sin embargo, que el texto mantendrá una importante ambigüedad al respecto. El artículo 2 de la sección segunda establece que para poder determinar si la mayoría favorable a la independencia es clara deberán tenerse en cuenta los siguientes factores: a) la cantidad de sufragios válidos emitidos a favor de la secesión; b) el porcentaje de electores inscritos que ha participado en el referéndum; y c) otros factores o circunstancias que se consideren relevantes. Sobre esta base, será la Cámara de los Comunes la encargada de afirmar si el requisito de la claridad ha sido satisfecho (artículo 1, sección segunda). Para fijar su posición, se añade, la Cámara tendrá en cuenta las opiniones de todos los particos políticos representados en la asamblea de la provincia concernida, todas las declaraciones formales o resoluciones de los cuerpos legislativos o ejecutivos de las demás provincias, las declaraciones formales o resoluciones del Senado, y aquellas de los representantes de los pueblos aborígenes. Se huye, pues, de la formulación de una regla general sobre la mayoría necesaria para activar la negociación y el proceso de reforma constitucional (mayoría absoluta, de $3 / 5$, de $2 / 3 \ldots$..), optándose por una «comunitarización» del parecer sobre si la mayoría es clara (Aguado Renedo, 2019, p. 317).

Esta adaptación normativa del dictamen del Tribunal fue respondida por la Asamblea legislativa de Quebec con la aprobación en diciembre del 2000 de la Ilamada Ley 99. El artículo 4 de la misma dispone que «cuando el pueblo quebequés es consultado en referéndum convocado en virtud de la Ley sobre la consulta popular, la opción ganadora es aquella que obtiene la mayoría de los votos declarados válidos, es decir, el cincuenta por ciento de tales votos más un voto». La norma fue impugnada por un particular ante la Corte Superior de la provincia de Quebec, que dictó sentencia en abril de $2018^{31}$ declarando su plena constitucionalidad. El tribunal apoya su decisión en dos argumentos esenciales: i) el artículo 4 no hace sino «reiterar lo que ha sido siempre la regla en los referendos celebrados en Quebec y en Canadá». Así, añade, «el hecho de que la opción ganadora sea aquella que logre la mayoría de los

\footnotetext{
${ }^{29}$ López Basaguren (2013, p. 81) subraya que el surgimiento de esa obligación de todas las partes a negociar tras la verificación del doble requisito de claridad implica que ninguna de ellas puede tratar de imponer sus posiciones de manera férrea. Así, las demás provincias y el gobierno federal no «pueden ejercer sus derechos de forma que lleven a una negación absoluta de los derechos de Quebec», y, paralelamente, la provincia de Quebec, «en la medida en que ejerza sus derechos respetando los derechos de los demás, puede pretender la secesión y tratar de lograrla a través de la negociación».

${ }^{30}$ Accesible en: https://laws-lois.justice.gc.ca/pdf/c-31.8.pdf

312018 QCCS 1586 (Caso Henderson c. Procureur générale du Québec).
} 
votos declarados válidos, por ejemplo el cincuenta por ciento más uno, ha existido siempre, sin que haya sido nunca cuestionada» (párrafos 492 y 493); ii) el resultado de la consulta será en todo caso consultivo, correspondiendo en última instancia a las autoridades representativas la decisión de impulsar el proceso de diálogo al que se refirió en su día el Tribunal Supremo de cara a la reforma constitucional (párrafos 508 y 509).

Ocurre, sin embargo, que declarar una opción ganadora, aunque el referéndum sea calificado de meramente consultivo, puede arrojar problemas no menores. Como reiteraba Alzaga (1980, p. 587), es difícil imaginar que los representantes de un territorio puedan desconocer la postura declarada victoriosa en la consulta realizada a los ciudadanos. Y parece evidente que la mayoría que habilite a declarar tal victoria no puede ser la misma para un referéndum sobre una cuestión menor que para otro referido a cuestiones de gran relevancia como la secesión de un territorio. En palabras de Aguado Renedo (2019, p. 322):

la regla de la mera mayoría, que puede servir para supuestos, por así decir, ordinarios, se vuelve muy distinta cuando se trata de decisiones que son realmente trascendentales, más que en el sentido de que impliquen consecuencias relevantes para la comunidad política afectada por el resultado de la decisión, en el de que afecte a la existencia misma de esa comunidad política.

En resumidas cuentas, y esto es lo que trasciende al criterio asentado por las nuevas Directrices de la Comisión de Venecia, cuando el electorado ha de pronunciarse sobre asuntos de relevancia constitucional esencial, permitir que la ruptura del statu quo pueda realizarse por una mayoría simple o absoluta no resulta razonable. Siguiendo con el criterio de Aguado Renedo (2019, p. 327-238), ejemplos de este tipo de asuntos serían i) decisiones que impliquen un cambio en la configuración existencial de la comunidad política, como la separación o agregación territoriales o la modificación del estatus constitucional de un territorio; ii) la afectación a derechos fundamentales cuasi absolutos; o iii) la integración en estructuras supranacionales a las que se cedan competencias derivadas de la Constitución.

El segundo supuesto en que la Comisión de Venecia admite la posibilidad de instaurar un quórum de aprobación sería el de la previsión de una mayoría múltiple, es decir, la exigencia de que la propuesta deba ser apoyada tanto por la mayoría de los ciudadanos del país como por la mayoría de las entidades territoriales en que se organiza. Se añade que tal opción es particularmente aceptable en el ámbito de las revisiones constitucionales. Pues bien, tenemos un ejemplo de este tipo de quórum especial en Suiza, cuya Constitución dispone en su artículo 195 que toda reforma de la misma, total o parcial, deberá ser ratificada «por el pueblo y los cantones» 32 . Así, las modificaciones del texto supremo, ya sean de iniciativa parlamentaria o popular, solo podrán llevarse a término si se obtiene la mayoría de votos favorables en el conjunto del país junto con una mayoría de cantones a favor de la reforma. En este sentido, la opción que obtenga más votos en cada cantón será la que marque el signo del voto del mismo.

La doble mayoría nació en la Constitución de 1848 como un pacto entre los cantones protestantes y los católicos con el fin de proteger los intereses de los cantones del centro del país, menos poblados y desarrollados industrialmente, y más conservadores (Sáenz Royo, 2016, p. 93). La consecuencia más evidente de este diseño reside en que el listón de la reforma constitucional se pone muy alto,

\footnotetext{
32 Garrido López (2018, p. 159) explica que en Australia la reforma constitucional aplica la misma regla, exigiéndose una mayoría de votos a favor en el global del Estado y en cuatro de los seis estados federados.
} 
exigiéndose una doble legitimidad, popular y cantonal, para que el proceso sea exitoso. Ello ha contribuido a la estabilidad de la política suiza (Muller y Vatter, 2020, p. 344). Ahora bien, como el voto de todos los cantones cuenta lo mismo ${ }^{33}$, un veto de los cantones interiores, con escaso número de habitantes y generalmente más conservadores, podría ser conflictivo en términos democráticos ${ }^{34}$. De modo que los ciudadanos conservadores de estos cantones tendrían un poderoso arma en sus manos. En opinión de Muller y Vatter (2020, p. 344), «esta desigualdad en el trato ciudadano es generalmente aceptada como el precio a pagar por la igualdad federal y la estabilidad».

Para finalizar este repaso por las novedades introducidas en el ámbito de las reglas específicas de las Directrices, debemos acudir a su apartado 9, dedicado a la fecha del referéndum. Así, en primer lugar, el texto establece que «en ningún caso el período mínimo entre la convocatoria del referéndum y el día de la celebración será menor a cuatro semanas». Se colma así una relevante laguna del antiguo Código, censurando la posibilidad de celebrar consultas inmediatamente después de su convocatoria. Inevitable en este punto recordar el referéndum propuesto por el primer ministro griego, Alexis Tsipras, sobre el plan de rescate presentado por la Unión Europea, el Banco Central Europeo y el Fondo Monetario Internacional a mediados de 2015. El Parlamento del país autorizó la propuesta gubernamental el día 28 de junio, celebrándose la votación popular el día 5 de julio. Es decir, los ciudadanos griegos tuvieron menos de una semana para formar su opinión sobre un aspecto tan complejo como las condiciones de un rescate financiero internacional. En circunstancias tales, la emisión de un voto libre y consciente resulta una quimera ${ }^{35}$.

En segundo lugar, el apartado 9 establece que «la ley deberá prever un plazo máximo entre la presentación de las firmas para un referéndum o una iniciativa popular y la votación». La razón de esta previsión es clara: si la normativa en materia de un referéndum no previera ese espacio de tiempo máximo que ha de mediar entre la consecución de las firmas requeridas y la celebración de la votación, ello quedaría en manos de las autoridades, con la consiguiente merma en la capacidad de control ciudadano del instrumento.

Por último, el apartado establece la conveniencia de «no celebrar elecciones y referendos en un mismo día si el referendo versa sobre la institución que se enfrenta a la elección». Así pues, más allá de tal supuesto concreto, en que parece razonable

\footnotetext{
${ }^{33}$ Con la única excepción de los medios cantones, que disponen de medio voto (art. 142.4 de la Constitución suiza). Son: Obwald, Nidwald, Bâle-Ville, Bâle-Campagne, Appenzell Rhodes-Extérieures, Appenzell Rhodes-Intérieures.

${ }^{34}$ Entre 1866 y 2018 se han producido trece casos de choque entre la mayoría popular y la cantonal en referendos constitucionales, cinco de los cuales han tenido lugar desde 1994. De los trece casos producidos, en nueve de ellos la mayoría cantonal ha vencido -en el sentido de que su criterio se ha impuesto. Datos extraídos de Muller y Vatter (2020, p. 348). En opinión de Dardanelli (2017, p. 246), «los mecanismos de la mayoría cantonal-agravados con el paso del tiempo por el creciente desequilibrio de la población entre cantones- conceden un poder de veto a una minoría extremadamente pequeña de la población suiza, que oscila de la media del $20-25 \%$ a un extremo teórico del $9 \%$. Todo esto, sumado al hecho de que los votos que requieren una doble mayoría cada vez son más frecuentes, al igual que los casos de desfase entre las mayorías populares y las cantonales, dificulta la adaptación del federalismo suizo a los principios democráticos». Kuenzi (2020) ha sugerido posibles adaptaciones de la regla de la doble mayoría para evitar que pueda suponer un freno conservador excesivo, entre las que destacan la posibilidad de circunvalar la necesidad de contar con la mayoría cantonal si la mayoría popular supera el $55 \%$ de los votos, o la dación de un valor desigual al voto de cada cantón en función de su peso demográfico.

${ }^{35}$ En palabras de Sáenz Royo (2016, p. 143), «las tácticas que tienden a evitar la deliberación son más efectivas en campañas breves».
} 
evitar la coincidencia, elecciones y referendos podrán celebrarse en unidad de acto, lo que puede resultar muy oportuno para reducir costes.

\section{Conclusiones}

Las democracias occidentales modernas se asientan sobre un predominante sistema representativo. Algunas de ellas, sin embargo, han incorporado a sus sistemas constitucionales herramientas de expresión directa de la ciudadanía, tratando así de complementar aquel sistema. La Comisión de Venecia, a través de sus Directrices sobre la celebración de referendos, subraya que es decisión exclusiva de cada Estado la inclusión -o no- de estos instrumentos y su alcance.

Ahora bien, si finalmente una Constitución decide abrir la puerta a la regulación de referendos e iniciativas, ha de ser consciente de la importancia capital que su concreto diseño posee. Si se desea que la democracia directa constituya un elemento verdaderamente útil para potenciar la vida democrática del país y hacer más partícipes a los ciudadanos de la toma de decisiones públicas, la configuración que se dé a estas instituciones lo es todo. Si esta es cuidada y ponderada, el referéndum será susceptible de ofrecer beneficios a la democracia. De lo contrario, será un peligro para ella.

Conocedora de esta realidad, la Comisión de Venecia aprobó en 2006 un Código de Buenas Prácticas en materia de referéndum. Aquella guía ha supuesto un importante referente tanto a nivel doctrinal como político. Ahora, la Comisión decide actualizar sus previsiones para adaptarse a las nuevas realidades y seguir combatiendo con renovada energía el uso espurio que del instrumento pueda hacerse. Como hemos analizado, cobran una gran relevancia elementos como el equilibrio de fuerzas en la campaña entre los partidarios de las dos alternativas planteadas, la redacción cuidadosa y clara de la pregunta sobre la que deliberarán los ciudadanos, los requisitos exigidos para que éstos pueden activar por sí mismos una consulta, o el plazo que se ofrezca al cuerpo electoral para que reflexione y adopte una decisión. Las nuevas Directrices afinan de un modo encomiable sus recomendaciones, y detallan las mejores regulaciones para hacer del referéndum un instrumento fiable y útil.

Una de las principales innovaciones del documento consiste en el otorgamiento de un nuevo y más alto estatus a la exigencia de que los referendos se convoquen siempre de conformidad con el ordenamiento constitucional de cada Estado. Lo contrario, como se ha remarcado, implicaría la anulación del Estado de Derecho en favor de un desnudo principio democrático, susceptible de las más lamentables instrumentalizaciones.

El referéndum, en definitiva, podrá ser un aliado de las promesas modernizadoras de las instituciones democráticas si se somete a precisas cautelas y garantías. El Derecho constitucional debe asumir esta tarea reguladora, anticiparse a posibles usos espurios de la figura y morigerar sus riesgos. La democracia no es equivalente a la simple expresión de la voluntad popular. El respeto a la ley y a los límites por ella establecidos resultan imprescindibles para su florecimiento y defensa. Las Directrices de la Comisión de Venecia, partiendo de esta idea, constituyen una magnífica asistencia a los miembros del Consejo de Europa para lograr este objetivo. No por casualidad, como enfatizaba Gianni Buquicchio, el nombre oficial de la institución es el de Comisión Europea para la Democracia a través del Derecho. 
Bibliografía

Aguado Renedo, C. (2019). Mitad más uno y principio democrático: Nuevas noticias de Quebec. Revista Española de Derecho Constitucional, 115, pp. 305-329.

Alzaga, Ó. (1980). Comentarios a la Constitución. Madrid, España: Ediciones del Foro.

Arias Guedón, S. (2020). El referéndum de iniciativa popular en los länder alemanes. En E. Sáenz Royo y C. Garrido López (coord.), El referéndum y su iniciativa en el Derecho comparado (pp. 149-166). Valencia, España: Tirant lo blanch.

Barrett, G. (2020). Modalidades y prácticas políticas relacionadas con los referéndums en Irlanda. En E. Sáenz Royo y C. Garrido López (coord.), El referéndum y su iniciativa en el Derecho comparado (pp. 55-79). Valencia, España: Tirant lo blanch.

Canale, G. (2016). Lo "spacchettamento": una (inammissibile) ipotesi lesiva del legittimo affidamento dei promotori del quesito unitario. Consulta online, 2, pp. 286-292.

Castellà, J. M. (2016). El referéndum sobre el Brexit. Una historia inacabada. Revista de Derecho Político, 97, pp. 297-334.

Castellà, J. M. (2020). Las directrices revisadas sobre la celebración de referendos de la Comisión de Venecia [video]. YouTube. https://www.youtube.com/watch?v=Ohn47QYjYLg

Cebrián Zazurca, E. (2020). El papel del referéndum en los procedimientos de reforma de la Constitución federal de la Confederación suiza. En E. Sáenz Royo y C. Garrido López (coord.), El referéndum y su iniciativa en el Derecho comparado (pp. 381-394). Valencia, España: Tirant lo blanch.

Dardanelli, P. (2017). El federalismo suizo: orígenes, evolución y desafíos. En W. Hofmeister y J. Tudela Aranda (ed.), Sistemas federales. Una comparación internacional (pp. 231-252). Zaragoza, España: Fundación Konrad Adenauer, Fundación Manuel Giménez Abad.

Font, J. y Gómez Fortes, B. (2014). ¿Cómo votamos en los referéndums?. Madrid, España: Catarata.

Garrido López, C. (2018). La utilidad del referéndum como acicate y contrapeso en las democracias representativas. Revista de Estudios Políticos, 181, pp. 135-165.

Gross, A. (2007). The design determines the quality - some criteria for determining the design and the quality of direct democracy. En Z. T. Pállinger, B. Kaufmann, W. Marxer y T. Schiller (ed.), Direct Democracy in Europe (pp. 64-70). Wiesbaden, Alemania: VS Verlag für Sozialwissenschaften.

Kobach, K.W. (1994). Switzerland. En D. Butler y A. Ranney (ed.), Referendums Around the World: The Growing Use of Direct Democracy (pp. 98-153). Washington, Estados Unidos: AEI Press.

Kuenzi, R. (2020). Switzerland is not unique in its double majority system. Swiss/nfo.ch. https://www.swissinfo.ch/eng/switzerland-is-not-unique-in-itsdouble-majority-system/46196670

Lignani, P. G. (2016). La difficile via giudiziaria allo spacchettamento. Lexltalia.it: Rivista Internet di Diritto Pubblico, 11, pp.

López Basaguren, A. (2013). Los referendos de secesión de Quebec y la doctrina de la Corte Suprema de Canadá. En E. Sáenz Royo y M. Contreras Casado, La participación política directa: referéndum y consultas populares (pp. 53-92). Zaragoza, España: Comuniter.

López Hernández, J. (2017). Referéndums: una inmersión rápida. Barcelona, España: Tibidabo.

López Rubio, D. (2020). Referéndum y deliberación. Revista Vasca de Administración Pública, 116, pp. 43-81.

Lupia, A y Johnston, R. (2001). Are Voters to Blame? Voter Competence and Elite Maneuvers in Referendums. En M. Mendelsohn y A. Parkin (ed.), Referendum 
Democracy (191-210), Londres, Reino Unido: Palgrave Macmillanop.

Muller, S. y Vatter, A. (2020). Switzerland (Swiss Confederation). En A. Griffiths, R. Chattopadhyay, J. Light y C. Stieren (ed.), The Forum of Federations Handbook of Federal Countries 2020 (pp. 341-352), Palgrave Macmillan.

Requejo Rodríguez, P. (2020). El canto del cisne del referéndum de iniciativa compartida, Cuadernos Manuel Giménez Abad, 20, pp. 271-312.

Romboli, R. y Panizza, S. (2016). Aspettando il referendum (con el fiato sospeso): Limiti e contenuti della reforma costituzionale Renzi-Boschi. Torino, Italia: Giappichelli.

Sáenz Royo, E. (2016). La regulación y la práctica del referéndum en Suiza, Revista de Estudios Políticos, 171, pp. 71-104.

Sáenz Royo, E. (2018). El referéndum en España. Madrid, España: Marcial Pons.

Seijas Villadangos, E. (2020). Praxis y regulación del referéndum en el Reino Unido. En E. Sáenz Royo y C. Garrido López (coord.), El referéndum y su iniciativa en el Derecho comparado (pp. 105-148). Valencia, España: Tirant lo blanch.

Serdült. U. (2018). Switzerland. En M. Qvortrup (ed.), Referendums Around the World (pp. 47-112), Cham: Palgrave Macmillan. 